\title{
The Logic and Language of IT Service Management
}

\author{
John Beachboard and Kregg Aytes \\ Idaho State University, Pocatello, Idaho, USA
}

beach@isu.edu aytekreg@isu.edu

\begin{abstract}
IT Service management (ITSM) practices are increasingly being adopted for use in commercial and not-for-profit enterprises around the world. While ITSM is primarily associated with improving the efficiency and effectiveness of the internal management practices of the IT service activity, the most recent release of the IT Infrastructure Library (ITIL) v. 3 identifies service strategy and service design practices intended to ensure that IT management investment and practices are truly aligned with enterprise needs. However, to be successfully implemented, service strategy and service design development requires the knowledgeable participation of business process owners. This essay briefly introduces IT service management practices and concepts required by all business professionals wishing to contribute to the alignment of IT investment and practices with business needs.
\end{abstract}

Keywords: IT Infrastructure Library, ITIL, IT service management, service level agreements, service catalogs, business IT alignment

\section{Introduction}

IT Service Management (ITSM) is a process-based practice designed to align the delivery of IT services with needs of the enterprise. ITSM emphasizes the customer's perspective on how IT services contribute to the business. ITSM practices rely on the business or customer perspective to design and implement IT services that meet the business's needs.

Our presentation of ITSM concept is based on IT Infrastructure Library (ITIL) ${ }^{\circledR}$ framework that was developed in the United Kingdom and later incorporated into an International Standards Organization (ISO) 20000 (Iqbal \& Nieves, 2007; Lloyd \& Rudd, 2007). There are other ITSM frameworks but this one is the most widely accepted and is not vendor-proprietary (if you don't know what vendor-proprietary is, check out the Wiki article on vendor lock-in at http://en.wikipedia.org/wiki/Vendor_lock-in.

If you are to understand IT service management, it is important to have a reasonably good under-

Material published as part of this publication, either on-line or in print, is copyrighted by the Informing Science Institute. Permission to make digital or paper copy of part or all of these works for personal or classroom use is granted without fee provided that the copies are not made or distributed for profit or commercial advantage AND that copies 1) bear this notice in full and 2) give the full citation on the first page. It is permissible to abstract these works so long as credit is given. To copy in all other cases or to republish or to post on a server or to redistribute to lists requires specific permission and payment of a fee. Contact Publisher@InformingScience.org to request redistribution permission. standing of what services are and what they are not. That is, we need to distinguish between goods and services. A colleague of ours describes what he calls the drop test to distinguish services from goods. Goods are tangible; If you can drop a purchase and it lands on your foot, that purchase is a good. If you make a purchase but have nothing to drop on your foot, the purchase is a service; services are intangible. In truth, 
much of what we buy is a hybrid mixture of goods and services. For example,' restaurants are considered a service industry, but they deliver food (goods) to the table.

ITIL ${ }^{\circledR}$ defines services as a means of delivering value to customers without the customer having to take ownership of, or responsibility for, the assets required to deliver that value. The definition might sound a little confusing, but the concept is quite simple. In the restaurant example, we expect to be served a good tasting meal in the expected price-range. We don't need to buy the food, hire the cook or wash the dishes. We get the value of eating a good meal without having to go through the all the hassle of preparing and serving it, or even cleaning up afterwards.

Automotive repair is also a part of the service industry. The value delivered is repaired cars. The car owner does not need to hire the mechanic, purchase the tools, or lease the building where repairs will be made. He or she simply drops off the car off to be repaired and picks it up and pays for it when the repairs are finished. Auto repair provides another good example of hybrid services as "parts" are often installed during the repair.

The management of services is somewhat different than the management of goods. Services are typically consumed when they are produced; thus an enterprise cannot stockpile or inventory services for later use. For example, flying passengers from New York to London is a service. The number and seating capacity of available jets limits our capacity to fly passengers. We cannot fly empty planes back and forth to store up capacity for particularly busy days. Since we can't build up an inventory of empty seats, capacity management is critical to service management. We must plan to have adequate supply on hand to meet the demand at the time the demand actually occurs. Otherwise, our potential customers will simply fly with another airline.

Secondly, services are experienced as much as consumed. There are many ways to fly between New York and London. One passenger might fly business class with a commercial carrier while another might make the same flight in the back of a military cargo jet. While both flights may get the passengers to their intended destinations, we assure you that the experiences are very different. Service managers attempt to match the quality of services provided to their customers' expectations - even if this means attempting to manage customer expectations.

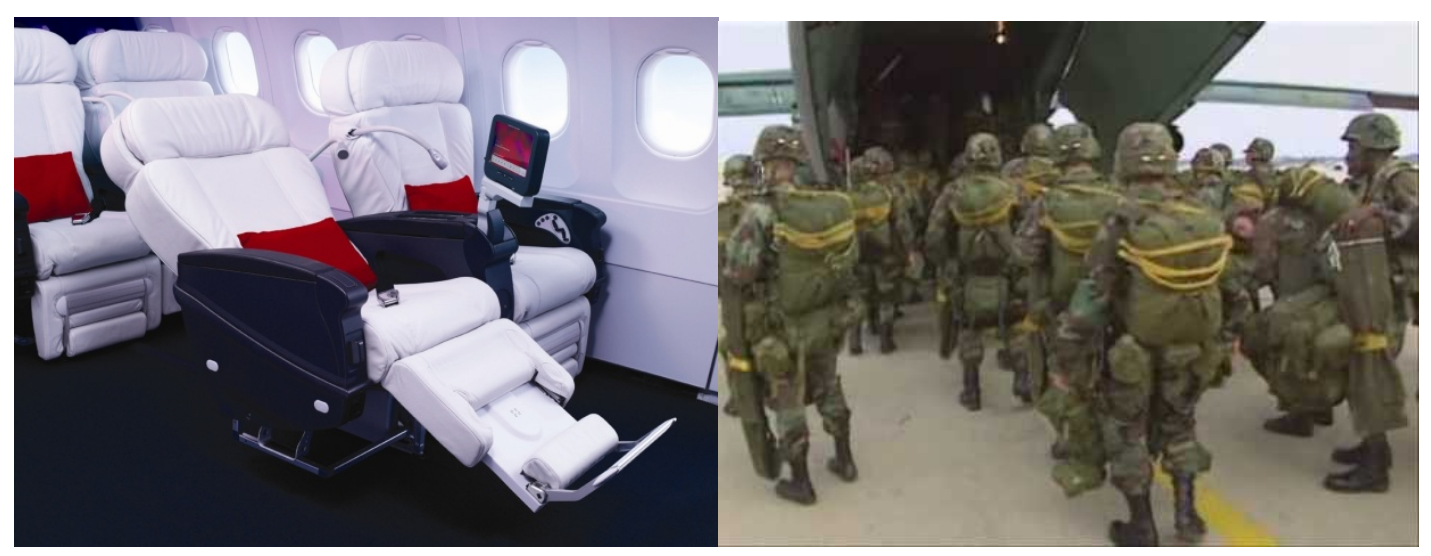

How would you rather fly: first class or military transport?

Getting back to our service definition, we value being flown from New York to London without having to purchase, maintain or fly the plane. We receive value without having to take ownership of or responsibility for the assets required to deliver that value. 
Email, accounting, and inventory systems are examples of IT services. Each of these "systems" is comprised of multiple technical components (e.g., hardware software and communications capabilities) and additionally require technical staff to keep them running. Business users typically do not want to worry about hardware, software or communications. They just want to send their email, generate financial statements, or check the inventory.

The adoption of the term IT services is explicitly intended to promote more effective communication between the business and IT staffs. Historically, IT professionals have relied on technical terms to describe business systems (e.g. LANs, WANs, ERPs, DBMSs, OLAP), terms that hold little or no meaning for most business users. IT Service Management (ITSM) attempts to get around this communications mismatch by defining IT services in terms that makes sense to the business user. So rather than reporting a router failure, IT might report disruption of email service or the web-based order entry service. By speaking in terms of services, enterprise management can more readily understand business consequences of the failure and adjust business operations as required.

\section{IT Service Management (ITSM) and the Alignment of IT Investments with Business Strategy}

IT service management, which primarily describes the many technical and managerial processes and principles associated with the effective and efficient planning, delivery, and operation of IT services, is fundamentally about achieving IT service/business alignment. The key to aligning IT services with business strategy (or needs) is recognizing the value that IT services provide to business processes so that neither too much nor too little is invested in delivering those services.

Business processes, simply defined, are structured sets of activities designed to achieve some intended purposes. If we are unprepared to value business processes and analyze how IT services support those processes, we have no rational basis for determining the appropriateness of the enterprise's IT investments. This logic drives the need for business managers to identify valueproducing business processes and understand the extent to which they depend upon IT services. For example, if the point-of-sales system at a grocery store goes down for two hours, store management should have some understanding of what that would mean in terms of lost sales, employee hours required to restock abandoned groceries, even spoilage. Perhaps such a calculation might be hard to justify if management is only responsible for a single store. But if it is a grocery chain with potentially a thousand stores, understanding outage costs could significantly impact the decision to make infrastructure upgrades required to increase service reliability.

Identifying critical IT services can be more challenging than you might expect. As depicted in Figure 1, there can be one-to-many and many-to-many links between IT services and business processes. For example, one IT service, an enterprise resource planning (ERP) system or the email service, might support multiple business processes while another a different IT service might only support a single business process (a web service that supports only supports online sale of train tickets). (An integrated business management system is intended to support all facets of the business, including planning, logistics, operations (whether manufacturing or services), and marketing.) Businesses need to understand which IT service support which business processes so that the management understands the consequences of various types of IT service failures. 


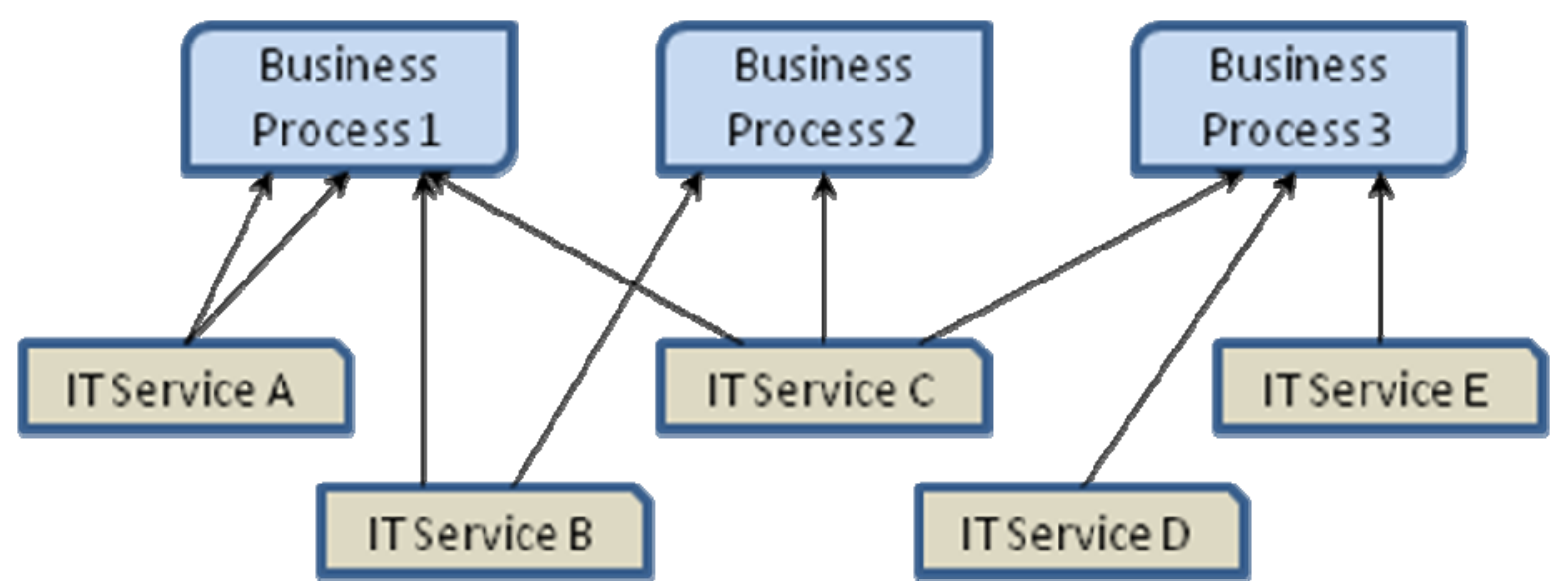

Figure 1. Specifying Critical IT Services

The issue is important because, all else being equal, increasing the reliability of service will likely increase the cost of providing the service. That is, higher levels of system performance, availability and security are more expensive to provide. We do not want to spend too much or too little for our IT services. For example, if a business spends $\$ 2,000$ each for 500 high-performance desktop workstations when $\$ 600$ PCs would work just as well, it has just wasted $\$ 700,000$ - more if you add the cost of maintenance. On the other hand, the business that won't spend $\$ 6,000$ to upgrade its web server may end up losing much more than $\$ 6,000$ in sales. The second business would be spending too little. We want to shoot for an appropriate level of service quality to meet the business's needs. Figuring out how much to spend takes both business and IT knowledge.

Value for enterprises resides fundamentally in their business processes. IT services have no intrinsic value. The worth of an IT service must be calculated on the basis of its contribution to the business process(es) it supports. Thus, the "business" value of an IT service can be no greater than the value of the supported business or processes.

ITIL $®$ conceptualizes service value as a function of a service's utility and warranty. IT service utility refers to the functionality delivered by the service, the features of the service that benefit the performance of the business process: e.g., automating seat selection and reservations during an airline's ticket sales process. Service warranty is concerned with the quality of the service provided. Is the seat reservation system available when it is needed? Does the transaction execute fast enough to avoid frustrating the customer? Is the seat reservation accurate? Both utility and warranty must be considered in evaluating service value. If the IT service does not provide the needed features, great speed and reliability mean nothing. Conversely, wonderful features have little value if the users have no assurance the service will actually be available when needed.

So how might one go about identifying business processes, IT services, and appropriate utility and warranty requirements for those services?

\section{IT Service Management and the Design of IT Services}

IT Service level management can improve the business/IT relationship by ensuring that the IT activity and its customers have a clear understanding of the IT services to be delivered. We use the term customer rather than user because we need to emphasize we are primarily, albeit not solely, concerned with the customer who orders or pays for the IT service, not the users who may actually use the service. (Think about this a bit and be sure to raise a question in class if the above logic seems unclear.) When we write about IT service customers we are most commonly 
referring to business process owners (if they have been identified) or functional managers most responsible for the performance of the business process. In a business context, these process owners may or may not be actually paying for the services received as many enterprises centrally fund their IT support. The main idea is that the IT staff needs to communicate with the business managers who are in the best position to identify and validate new requirements and understand the business consequences of IT service failure.

The ITIL $®$ framework prescribes a multitude of documents to be created during service design (Lloyd \& Rudd, 2007). Two documents are of particular interest to non-IT management: the enterprise's IT service catalog and supporting service level agreements (SLAs). The development of these two documents provides a disciplined approach to aligning IT services with their enterprise strategy.

Business value resides in the business processes, and the value of IT services is calculated by assessing the extent to which IT services support business processes and associated business decisions. This is the simple logic that drives the development of service catalogs and SLAs.

\section{Service Catalogs and Service-level Agreements (SLAs)}

ITIL ${ }^{\circledR}$ defines service catalogs and service level agreements (SLA) as follows:

Service Catalog: a database or structured document with information about all operational services, including those available for deployment.

Service Level Agreement (SLA): An agreement negotiated between the IT service provider and the customer that documents service level targets (i.e., service levels promised by the service provider) and specifies the responsibilities of the service provider and the customer.

Under ITIL ${ }^{\circ}$, the service catalog contains two layers of documentation: the business service catalog and the technical services catalog. (The IT service vendor community has described a user request catalog which may be seen as a separate catalog or an enhancement of the business service catalog that documents and ideally automates IT service requests.) Both catalogs identify and describe IT services. The business service catalog is oriented to the needs of the customer. It describes IT services available for use and documents their relationship to business processes. The technical services catalog is designed to guide the IT service provider. It documents the relationship among IT services and the technical elements within the IT infrastructure required to support the IT service. We are not going to worry about the technical services catalog in this paper (just wanted you to know it's there).

The SLA is a negotiated agreement that documents the responsibilities of the participating parties regarding the delivery of the IT services (specified in the service catalog). The SLA also documents service performance levels to be achieved. Service catalogs and SLAs contain much common information and many commercial service management applications from vendors such as IBM, CA, BMC, and Axios, and often store all service related data in a common database (see Table 1 which illustrates how much of the information is repeated between the two documents).

As with a mail order catalog, the service catalog should provide information that helps customers make their purchasing decisions. For example, a separate section of the catalog might describe the terms of service such as: payment, shipping, quality guarantees, return policies. Consequently, both service catalogs and SLAs contain service descriptions, information on service hours, and points of contact.

SLAs describe responsibilities in terms of obligations (customer as well as IT activity obligations) rather than detailing the ordering procedures. Given the varying needs of service custom- 
ers within the enterprise and the possibility of using multiple IT service providers, enterprises might well negotiate multiple SLAs.

Table 1. Suggested Elements for Inclusion in Catalogs and Service Level Agreements

\begin{tabular}{|c|c|c|c|}
\hline Element & Service Catalog & SLA & Explanation \\
\hline Service Name & $\mathrm{X}$ & $\mathrm{X}$ & A short title for the service \\
\hline $\begin{array}{l}\text { Service } \\
\text { Description }\end{array}$ & $\mathrm{X}$ & $\mathrm{X}$ & $\begin{array}{l}\text { Sufficient detail to unambiguously identify } \\
\text { the service. May include business processes } \\
\text { supported, deliverables, brief description of } \\
\text { functionality. }\end{array}$ \\
\hline Signatories & & $\mathrm{X}$ & $\begin{array}{l}\text { IT and business owner representatives } \\
\text { authorized to enter into subject agreement. }\end{array}$ \\
\hline $\begin{array}{l}\text { Supporting } \\
\text { Services }\end{array}$ & $\mathrm{X}$ & & $\begin{array}{l}\text { Other services upon which the service } \\
\text { depends. }\end{array}$ \\
\hline $\begin{array}{l}\text { Business Process } \\
\text { Owner }\end{array}$ & $\mathrm{X}$ & & $\begin{array}{l}\text { The business element with final authority to } \\
\text { approve changes to the service functionality. }\end{array}$ \\
\hline $\begin{array}{l}\text { Service } \\
\text { Manager(s) }\end{array}$ & $\mathrm{X}$ & & $\begin{array}{l}\text { IT manager responsible for delivering IT } \\
\text { service. }\end{array}$ \\
\hline Business Impact & $\mathrm{X}$ & & $\begin{array}{l}\text { Business consequences of service failure, } \\
\text { e.g., severe, moderate, low. May also be } \\
\text { included in service description. }\end{array}$ \\
\hline
\end{tabular}

Aligns with business impact; informs

Business Priority $\quad \mathrm{X} \quad$ customer of where this service stacks up in terms of the IT activity's service restoration priorities.

$\begin{array}{lll}\begin{array}{l}\text { Service Level } \\ \text { Agreement }\end{array} & \text { N } & \begin{array}{l}\text { A service catalog may detail service levels or } \\ \text { report existence or non-existence of } \\ \text { associated SLA. }\end{array}\end{array}$

Customer
Support

Procedures customers are expected to follow when requesting new service or reporting problems.

Hours when service is available; may $\begin{array}{lll}\text { Service Hours } & \text { X } & \begin{array}{l}\text { identify different/limited services available } \\ \text { during non-business hours relative to those }\end{array}\end{array}$ available during normal business hours.

Business
Contacts $\quad \mathrm{X} \quad \begin{aligned} & \text { Business unit staff or manager to be } \\ & \text { contacted by IT activity to report service } \\ & \text { changes or disruptions. }\end{aligned}$

$\begin{array}{lll}\begin{array}{l}\text { Escalation } \\ \text { Contacts }\end{array} & \text { X } & \begin{array}{l}\text { Escalation point that customers/users can } \\ \text { contact if dissatisfied by the initial level of IT } \\ \text { support. }\end{array}\end{array}$

$\begin{array}{lll}\begin{array}{l}\text { Service } \\ \text { Reports/Metrics }\end{array} \quad \mathrm{X} & \begin{array}{l}\text { Identifies the frequency and content of } \\ \text { service reports to be provided by IT activity } \\ \text { to service customers. }\end{array}\end{array}$




\begin{tabular}{|c|c|c|c|}
\hline Element & Service Catalog & SLA & Explanation \\
\hline Service Reviews & $\mathrm{X}$ & $\mathrm{X}$ & $\begin{array}{l}\text { Schedule for formal reviews to assess overall } \\
\text { service performance and identify issues that } \\
\text { might require service change requests or re- } \\
\text { negotiation of the SLA. }\end{array}$ \\
\hline Security & $\mathrm{X}$ & $\mathrm{X}$ & $\begin{array}{l}\text { This item may be as simple as identification } \\
\text { of a service category or may contain detailed } \\
\text { description of risk mitigation measures } \\
\text { applied and customer obligations for } \\
\text { maintaining service security. }\end{array}$ \\
\hline $\begin{array}{l}\text { Scope of } \\
\text { Agreement }\end{array}$ & & $\mathrm{X}$ & $\begin{array}{l}\text { Explicitly identifies temporal, organizational, } \\
\text { geographical and technical scope of the } \\
\text { agreement. }\end{array}$ \\
\hline $\begin{array}{l}\text { Service } \\
\text { Availability }\end{array}$ & & $\mathrm{X}$ & $\begin{array}{l}\text { Target availability levels that the IT activity } \\
\text { will seek to achieve; typically expressed as a } \\
\text { percentage of time for designated } \\
\text { measurement periods. }\end{array}$ \\
\hline $\begin{array}{l}\text { Service } \\
\text { Reliability }\end{array}$ & & $\mathrm{X}$ & $\begin{array}{l}\text { Maximum number of unscheduled service } \\
\text { breaks occurring during designated } \\
\text { measurement period. }\end{array}$ \\
\hline $\begin{array}{l}\text { Service } \\
\text { Performance }\end{array}$ & & $X$ & $\begin{array}{l}\text { Service responsiveness, typically measured } \\
\text { in terms of a percentage of service responses } \\
\text { completing in less than the target response } \\
\text { time: e.g., } 98 \% \text { of transactions should } \\
\text { complete in two seconds or less. }\end{array}$ \\
\hline $\begin{array}{l}\text { Service } \\
\text { Continuity }\end{array}$ & & $\mathrm{X}$ & $\begin{array}{l}\text { Identifies whether service is included in } \\
\text { enterprise's service continuity plan; typically } \\
\text { would estimate the time it would take to } \\
\text { restore services in the event of catastrophic } \\
\text { service outages. }\end{array}$ \\
\hline Service Charges & $\mathrm{X}$ & $\mathrm{X}$ & $\begin{array}{l}\text { The amount customers will be charged for } \\
\text { usage and penalties paid by provider should } \\
\text { targets not be achieved. }\end{array}$ \\
\hline Responsibilities & & $\mathrm{X}$ & $\begin{array}{l}\text { IT activity and customer responsibilities with } \\
\text { respect to service delivery and performance. }\end{array}$ \\
\hline Contact Points & & $\mathrm{X}$ & $\begin{array}{l}\text { Customer and IT activity points of contact } \\
\text { for maintenance of the SLA. }\end{array}$ \\
\hline Amendments & & $\mathrm{X}$ & $\begin{array}{l}\text { Record of authorized changes to provisions } \\
\text { of the SLA. }\end{array}$ \\
\hline
\end{tabular}

Table 1 briefly summarizes the types of information included in service catalogs. Templates and samples can be found on the internet or purchased from vendors. But understand that while the fundamental concepts underlying the preparation of these documents is fairly straightforward, the real challenge lies in the analysis required to usefully apply the template. For now, we need to recognize the logic of these two documents and how they can be used to help a business align its IT investments with its business strategy. The service catalog identifies the IT services on which the business depends. A critical element of the service catalog is the documenting the linkage between the IT services and the business processes that the IT services support. As is discussed 
in more detail below, the business process owners need to determine the extent to which important business processes rely on supporting IT services. This allows the business process owners to think about the business consequences of IT service failures and specify appropriate performance, reliability and security (i.e., utility) specifications for incorporation into the service level agreement.

\section{Establishing the Service Baseline: Creating a Service Catalog and Service Level Agreement for Existing IT Services}

During the 2000 Super Bowl, Electronic Data Systems, Inc. (EDS) introduced a commercial depicting a jumbo jet being assembled while in flight. The commercial closes with the message: "In a sense, this is what we do. We build your digital business even while you're up and running." The commercial speaks to one of the primary challenges faced by IT professionals upgrading enterprise IT services. The joke is that you can't build jumbo jets while they're in the air; the irony is that is pretty much how we build IT services. Newly formed enterprises may start from ground zero, but most organizations have legacy systems that must be accommodated while they plan for future improvements.

Service design is intuitively associated with the design of new services. We introduce the topic by describing how to bring existing services under management. Our rationale is that if an enterprise cannot muster the energy to bring existing services under management, it is unlikely that it will have much luck applying service design principles to new services because of the discipline and learning which must occur. Starting with existing business processes and IT services permits participants to become acquainted with the strengths and limitations of these techniques while operating in the context of known requirements and capabilities.

Due to the workload associated with implementing a comprehensive service catalog and SLA, many practitioners recommend phasing in their development. Enterprises might do well to focus their initial attention on "important" IT services (those that can be directly mapped to the services identified in the strategic IT vision) or where service customers may be less than satisfied. Addressing recognized pain points can facilitate the involvement of key personnel and justify their effort by holding out the hope that the exercise will lead to improvements in service quality. The selection of "important" services is driven by a desire to demonstrate that IT service improvements can measurably improve business performance. Fundamental steps for documenting an enterprise's IT service baseline are as follows.

\section{Step 1. Identifying business processes and supporting IT services}

The first task is to identify and define business processes and IT services in a way that makes sense to the IT staff and business process owners. Ideally, the enterprise will have created a process architecture that identifies important business processes. We have a later module on business process management that addresses this issue in more detail. For now, we just want you to understand we need to agree on a set of processes that are important to the functioning of the enterprise to get this effort started. Again, it is not necessary to start by identifying all business processes. Start with the ones that matter most to the enterprise - either in terms of improving current operational performance or getting the enterprise in shape to implement a new strategy.

Once we have identified the business processes, we move to the identification of the supporting IT services. Historically, IT staffs have thought in terms of software applications. But, software applications may not make sense to the business user. For example, a web-based IT service can be accessed by dock workers to schedule, unload, distribute and record the receipt of incoming material. There may be multiple database applications supporting these dock management business processes: one for scheduling, one that provides the truck manifest, a different one that lets 
the dock workers know where to distribute the material, and finally, an application that reconciles the material delivered with orders and authorizes payment. From a customer perspective, neither the number of underlying database applications nor various elements comprising the technical infrastructure required to deliver the service matters. What does matter is do they have the tools they need to perform their jobs. It may make more sense to identify one dock management support service, even though it relies on multiple databases and database applications.

Unfortunately, we cannot provide definitive guidance regarding how to identify IT services. In terms of our "loading dock" example, one enterprise may identify a single IT service, supporting all dock receiving activities, while another may distinguish between receiving and the order reconciliation services. We advise that the participants explicitly consider the issue of granularity in characterizing a service or activity. Too little granularity may combine too many functions under a single service description, undermining management's ability to adequately assess the value contributed by various elements or to realistically specify service warranties. Conversely, when the service descriptions become too granular, the effort can become overwhelming in terms of the original production of the service catalog and SLA.

Furthermore, IT professionals should not dictate service definitions based on their understanding of the technical elements comprising service. The business process owners, in consultation with users and the IT staff, need to define IT services at a level of detail that aligns with the performance of important business activities. Thus begin the conversations that lead to effective alignment of information technology with the enterprise strategy.

Remember Pareto's Law, the $80 / 20$ rule, which suggests that 80 percent of the value is derived if derived from 20 percent of the effort. Start with IT services that matter: services that must be operational to keep the business running. Of these, focus on the services that are problematic or could use improvement. Clearly identify the business processes supported by the IT services; there may be more than one. Then ensure that the business process owners work with IT to define and describe the desired service in a way that makes business sense for both sets of stakeholders. If core business processes are dependent on multiple IT services, it may be useful to develop service descriptions in parallel. From both technical and business perspectives, service and process boundaries can be a bit fuzzy. The object is to impose boundaries upon the business processes and IT services that make business sense.

Don't worry if the enterprise doesn't nail the service and process descriptions exactly right the first time out. There may not be one "exactly right" way (thinking in terms of granularity) to identify specific processes and services. You are not pouring concrete; you can come back and revise your descriptions if necessary.

\section{Step 2. Develop risk-based service level requirements}

Once the relevant parties reach agreement on the description of the relevant processes and services, the real work begins. The value of IT services is derived by assessing the degree to which they support business processes, not the actual cost of providing the service. A low-cost IT service critical to the functioning of a revenue-producing process may have greater value to the enterprise than a higher cost service supporting a less critical business process.

The analysis required to develop appropriate SLAs is more complicated than that required to develop service catalogs. Fortunately, methods do exist to wrestle with this beast, and they primarily come out of the information security discipline. In fact, information security is fundamentally concerned with the management of IT-related risk in order to decide how much to spend on protective measures. The same logic applies to establishing requirements for service reliability and performance. The underlying framework for conducting such analyses is: 
- Identifying organizational information assets, the data and IT services on which the organization depends (actions already discussed in steps one and two.)

- Identifying asset vulnerabilities, the susceptibility of the asset to breakdown or malicious attack. This is primarily a technical activity performed by security specialists.

- Identifying threats, objects, persons or incidents capable of exploiting vulnerabilities (also the responsibility of security specialists).

- Determining which risk mitigation techniques can be cost-effectively employed; mitigation should not cost more than the losses it is designed to avoid.

The enterprise needs to understand the costs and consequences of IT service failure in order to develop appropriate service-level targets (relative to availability, reliability, performance and confidentiality as described below). Business process owners need to accurately identify and assess the consequences resulting from IT service failures. Security specialists should provide information concerning vulnerabilities, threats, and their probabilities. But the estimation of asset values and consequences of service failure should reside with the business process owners. If there is a mismatch between the results of the detailed analysis of service level requirements performed during service design and the executive vision of service level requirements communicated in the strategic IT vision, then executive-level coordination is needed to resolve the discrepancies.

Since we are more accustomed to thinking about failure or loss of tangible items (such as products stolen off a loading dock) most of us do not have a good intuitive sense of what constitutes IT service failures. Unlike the loss of a bag of corn chips, information can be stolen and still be there. When thinking about IT service failures we are concerned with:

- Confidentiality: unauthorized persons obtaining the ability to view information that the service provider does not want them to see (e.g., someone accesses your health or financial information and posts it on the internet)

- Integrity: unauthorized and inappropriate changes to information occur (e.g., a student breaks into the university system and changes records concerning course completions and grades)

- Availability: the information or service cannot be accessed when required (e.g., the ATM machine is offline and you really need the cash)

When business process owners think about the consequences of IT service failures, they must consider what types of service failure really matter. For example, weather reporting or movie review websites are not directly concerned with confidentiality. The purpose of their IT services is to post information onto the web for all to see. Availability is an issue because their customers will probably start using other websites if they repeatedly find the sites unavailable. And if users depart, advertisers and site revenues depart as well. Integrity of posted information is important to these web services, but the liabilities associated with posting incorrect information are probably not as severe as those faced by some other types of businesses; their issue is primarily one of availability.

In contrast, online banks must be concerned with all three issues: confidentiality, integrity and availability of information stored on their IT systems. Legal and civil penalties may result from mishandling customer data. For example, the Gramm-Leach-Bliley Act of 1999 is a federal law that requires financial institutions to establish appropriate safeguards to protect customer data. Banks are also interested in maintaining the integrity of their financial records due to losses associated with unauthorized changes (imagine customers able to hack the system and change their 
account balances). And of course, customers are likely to change banks should they experience recurring outages when trying to conduct their business.

Coming to grips with the financial, legal, and ethical consequences associated with these types of IT service failures is a necessary step for developing appropriate service level targets for inclusion in negotiated SLAs. The issue is that increasing service level requirements for confidentiality, integrity and availability inevitably raises the cost of providing the IT service.

Although we are using the language of security and risk, this type of analysis is not limited to malicious threats. Accidents are just as capable of taking down a system. An administrator may spill a can of soda over a critical server or a backhoe may dig up an important communications cable. Service level requirements are concerned with the business consequences of service failure irrespective of the cause.

Consider an accounting firm that has all of its customer data stored on an in-house server. The firm regularly backs up the data but stores the backup data onsite. What would happen if the building burns down? What would the firm pay per year to reduce the probability of losing all of its data? It turns out that the cost of mitigating this particular risk would be relatively small: create duplicate copies of backups regularly and store them offsite. Now consider the same accounting firm, but this time the threat to the data is different. Perhaps the data are accessed by a criminal organization that intends to sell the data to a competitor or to commit identify theft. Not only are the financial and legal risks somewhat different in this case, the cost of reducing this type of risk likely will be higher. What should the firm pay to reduce the probability of data theft?

The answers to these types of questions drive the selection of target service levels, which in turn drive IT infrastructure investments. Too often, non-IT management is willing to delegate responsibility for answering these questions to its IT staff. IT staffs often turn to consultants for help. While IT and security professionals can better identify potential threats and threat probabilities, they should not be asked to evaluate the business consequences of IT service failures; this should be the responsibility of business process owners, in consultation with executive management. In fact, we discourage the use of consultants for estimating asset value and consequences of service failure as outsider may inflate loss estimates in a bid to sell more consulting services.

Without prior experience, the selection of appropriate service level targets is difficult. Business process owners need to think about the consequences resulting from various categories and durations of service failures. But that does not end their responsibilities. Process owners might be tempted to establish very high service level targets: e.g., 99.9999 percent service availability. But achieving such service levels would likely be very expensive. Tough business decisions must be made, and the enterprise executives and process owners need to make them.

It is during the discussion of service level requirements that the IT staff comes to truly understand the enterprise's IT needs and process owners learn about the cost constraints faced by IT in achieving desired service levels.

\section{Step 3. Prioritizing IT services}

So far we have emphasized the analysis of service level requirements on an individual service basis. But service catalogs need to communicate restoration priorities as well. Unfortunately multiple service failures can crop up at once. IT activities at some time or another will need to prioritize their service recovery work. However, it is difficult to clearly evaluate restoration priorities by examining one service at a time. Management requires an enterprise-wide perspective to categorize the criticality of IT services and establish the order in which they should be restored. An effective prioritization effort requires in-depth understanding of business processes, their inter-dependencies, legal and contractual obligations, and the extent to which business processes depend on IT services. 


\section{Step 4. Documenting the results and spreading the word}

While we have emphasized that the primary value in developing service catalogs and SLAs lies in the thinking and communication that go into their production, maximum benefit occurs when the service catalog and SLAs are actively used by the enterprise. An increasing number of enterprises are publishing their service catalogs and SLAs on intranet websites. An advantage of webbased publication is that usage of the documents is easily tracked. Finally, we advocate formal training be provided to the IT staff and IT service customers on proper use of these documents.

In a sense, these steps are repeated (with minor variations) when it comes to designing business processes and IT services or evaluating significant changes to existing ones.

\section{Potential Pitfalls}

An important factor contributing to the failure of service catalogs and SLAs to deliver expected value is that the effort to create these documents tends to originate in and be executed by the IT activity. And yet the primary objectives of a service catalog and SLA are to:

- Articulate the value of IT services in business terms

- Demonstrate that value by measuring and reporting on service delivery (in terms that make sense to service users and business process owners)

- Demonstrate that the IT activity understands the enterprise's business needs

To accomplish these objectives, the IT activity needs to understand what the business process owners care most about.

A second problem associated with unsuccessful service catalog implementation occurs when the participants are overly ambitious. A large enterprise may have thousands of business processes and hundreds of supporting IT services. Even small businesses may rely on a surprisingly large number of IT services to support their day-to-day operations. Consequently, the effort to develop a comprehensive service catalog documenting all business process/IT service relationships can be overwhelming. Success requires focus and discipline to manage the overall scope of the project while maximizing benefits accruing to the enterprise.

A third problem results when the process becomes overly bureaucratized. Just as with quality improvement programs such as Six Sigma or ISO 9000, there can be a tendency to focus on process rather than value the process is expected to deliver. Miniature fiefdoms can develop and what should be a valuable management activity can run amuck.

\section{Service Design Wrap-up}

We believe it is at the IT service design stage where the proverbial "rubber" of IT services "meets the road" of business alignment. We acknowledge that many successful enterprises do not follow the service design practices described in this chapter. Yet many business leaders complain that they are not receiving the return on their IT investments that they think they should.

IT management pundits have long called for improving the relationship between IT professionals and the user communities they support. However, the prescriptions for how such relationships might be enhanced have been vague at best. IT service management principles generally, and the practice of IT service design in particular, provide a vocabulary and method for building understanding and cooperation between the IT activity and business process owners and IT service users. While no vocabulary can dismiss the very real technical issues that IT professional face, the focus on service provides a means of shielding process owners from much of the complexity that 
goes into the technical design. We have seen no IT management process described that has a greater potential for enhancing the relationship between IT and business staffs.

There is a lot of information provided in this reading assignment and we recognize that you are likely to find it a bit confusing. We will do another in class exercise that should help these ideas make more sense.

\section{References}

Iqbal, M., \& Nieves, M. (2007). ITIL: Service strategy. United Kingdom: OGC.

Lloyd, V., \& Rudd, C. (2007). ITIL: Service design. United Kingdom: OGC.

\section{Biographies}

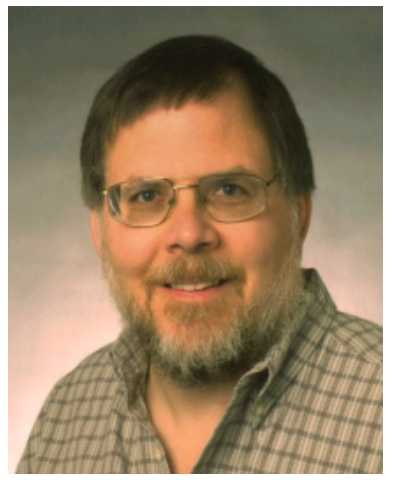

John C. Beachboard joined the Computer Information Systems faculty at Idaho State University in 2001. He completed the Ph.D. in Information Transfer and the M.S. in Information Resources Management at the School of Information Studies, Syracuse University. He holds an M.S. in Business Administration from Boston University and a B.S. in Public Administration from the University of Arizona. Dr. Beachboard has taught graduate courses in research methods, project management, and IT use in business, and undergraduate courses in IT management and systems architectures. He has held staff and management positions developing, implementing and operating information and telecommunications systems for the Department of Defense.

He is keenly interested in the development, application and effectiveness of information technology management policies in the private and public sectors.

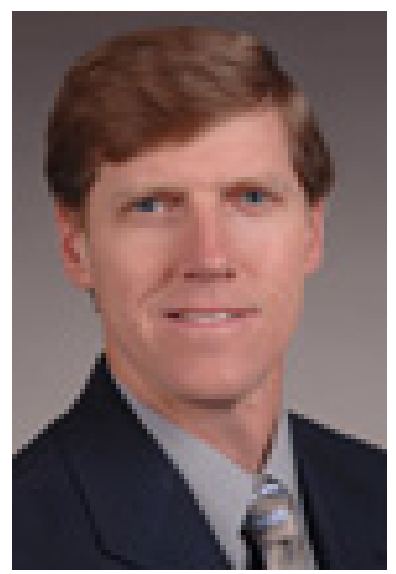

Kregg Aytes has been a member of the Computer Information Systems faculty at Idaho State University since 1993. He completed his $\mathrm{Ph} . \mathrm{D}$. at the University of Arizona in that same year. Kregg teaches graduate and undergraduate courses in CIS, served as CIS Department Chair, and has been Associate Dean since 2008. His research interests include information security, collaborative technologies and social media use by entrepreneurs. He also has a strong love of teaching and is interested in the application of IS content and skills across the business school curriculum. 